\title{
Cardiovascular risk profile of mothers of a Portuguese birth cohort: A survey 4 years after delivery ${ }^{2}$
}

\author{
Elisabete Alves *, Ana Henriques, Sofia Correia, Ana Cristina Santos, Ana Azevedo, Henrique Barros
}

Department of Clinical Epidemiology, Predictive Medicine and Public Health, University of Porto Medical School, Porto, Portugal Institute of Public Health - University of Porto, Porto, Portugal

\section{A R T I C L E I N F O}

Available online 9 July 2013

Keywords:

Cardiovascular diseases

Prevalence

Risk factors

Women's health

\section{A B S T R A C T}

Objectives. The aim of this study is to estimate the prevalence of smoking, low fruit and vegetable intake, sedentariness, overweight/obesity, abdominal obesity, hypertension, dyslipidemia and diabetes mellitus in mothers of a Portuguese birth cohort, 4 years after delivery.

Methods. A birth cohort was assembled at public maternities of Porto (2005-2006). Children and mothers were reevaluated 4 years later. In this analysis, 5435 women were included. Socioeconomic characteristics, smoking, diet and exercise were self-reported. Anthropometrics and blood pressure were measured. A subgroup of 2483 randomly selected women provided a fasting venous blood sample for lipid and glucose measurements.

Results. Overall, $25.3 \%$ women smoked, $71.5 \%$ consumed $<5$ portions of fruit and vegetables per day, $81.3 \%$ were sedentary, $31.4 \%$ were overweight, $21.3 \%$ obese and $31.8 \%$ had abdominal obesity. The prevalence of hypertension, dyslipidemia and diabetes mellitus was $8.7 \%, 18.5 \%$ and $0.9 \%$, respectively. At least one risk factor from each of the 3 groups (adverse lifestyles, adiposity and cardiometabolic comorbidities) was observed in $17.4 \%$ of women. Except for smoking, all risk factors were associated with unemployment, lower education and lower income.

Conclusions. The high prevalence of unfavorable lifestyles and adiposity, and the aggregation of risk factors emphasize the adverse cardiovascular risk profile at a young age.

(c) 2013 Elsevier Inc. All rights reserved.

\section{Introduction}

Cardiovascular diseases (CVD) are responsible for almost half of female deaths in Europe (Allender et al., 2008) and accounted for $36.3 \%$ of all deaths among women in Portugal in 2009 (Instituto Nacional de Estatística (INE), 2012). CVD are mainly attributable to classical risk factors, namely cigarette smoking, high blood pressure, high serum cholesterol, diabetes, overweight/obesity and adverse diet (Stamler, 2005). CVD mortality rates increase with the number of risk factors present in an individual, suggesting that the lower the risk factor profile, the lower the risk for CVD and all-cause mortality (Daviglus et al., 2004; Stamler, 2005).

Pregnancy brings a physiological stress that can uncover an underlying propensity for chronic disease (Sattar and Greer, 2002). In populations with universal free access to prenatal and postnatal care such as Portugal (DGS, 2001), pregnancy may constitute a good opportunity

\footnotetext{
Source (s) of funding: This work was supported by Fundação para a Ciência e a Tecnologia, Fundação Calouste Gulbenkian, Programa Operacional de Saúde Saúde XXI and Administração Regional de Saúde Norte.

* Corresponding author at: Department of Clinical Epidemiology, Predictive Medicine and Public Health, University of Porto Medical School, Alameda Prof. Hernâni Monteiro, 4200-319 Porto, Portugal. Fax: + 351225513653.

E-mail address: ealves@med.up.pt (E. Alves).
}

for health promotion and disease prevention (McBride et al., 2003), not only for the mothers but also for their children. Thus, the potential to achieve effective health promotion and disease prevention in lower socioeconomic positions (SEP), which are at higher cardiovascular risk, may be very important.

In this study, we aimed to estimate the prevalence of eight established cardiovascular risk factors (smoking, low fruit and vegetable intake, sedentariness, general overweight/obesity, abdominal obesity, hypertension, dyslipidemia and diabetes mellitus) in mothers of a Portuguese birth cohort, 4 years after delivery, and to describe their distribution by age, gravidity and indicators of SEP.

\section{Methods}

This study is based on the birth cohort Generation XXI, which has been described previously (Alves et al., 2012). The cohort was recruited at the 5 public maternity units covering the metropolitan area of Porto, Portugal (2005-2006). A total of 8495 mothers, who gave birth to 8647 infants, were enrolled in the cohort. At 4 years of the child's age, the cohort was re-evaluated (2009-2011). Overall, $67.4 \%$ of the mothers attended a face-to-face interview and physical examination at the study site, half of whom were randomly selected to provide a fasting blood sample.

Among the 5729 mothers who attended the face-to-face interview, we excluded 174 who were pregnant at the follow-up visit and 120 with at least 
one missing value on variables used in this study. The remaining 5435 women were included in the current analysis, 2483 (45.7\%) of whom had biochemical laboratorial data.

At the cohort's reevaluation, an average of 4 years after delivery (median: 51 months; range: 49-55), data were collected by trained interviewers using structured questionnaires. Socioeconomic characteristics, lifestyles and obstetric history of the mother were self-reported. Marital status was grouped in two categories, according to co-habitation with a partner. Educational level was considered as the number of completed years of education and categorized as $<4$ years, $5-9$ years, $10-12$ years and $>12$ years. Working condition was defined as employed, unemployed, housewife and others (student or retired) Household monthly income was inquired using previously defined categories: $<500 €, 500-1000 €, 1001-1500 €,>1500 €$ and women who didn't know or preferred not to answer. Gravidity was recorded as the number of pregnancies for each participant, before, after and including the index pregnancy.

Current smokers included daily (at least one cigarette per day) and occasional smokers (less than one cigarette per day), and ex-smokers did not smoke for at least 6 months. The frequency of fruits, vegetable soup and "vegetables on the dish" intake, without considering portion sizes, was assessed through questions adapted from a food frequency questionnaire, which has been previously validated in Portuguese adult non-pregnant adults (Lopes et al., 2007). Low fruit and vegetable intake was defined as the combination of items from any of these groups summing $<5$ per day. Physical exercise was considered as the structured and regular practice of any sport or physical exercise of mild, moderate or vigorous intensity.

Weight and height were measured and the mothers' body mass index (BMI) was categorized according to the World Health Organization (1998) as underweight $\left(<18.5 \mathrm{~kg} / \mathrm{m}^{2}\right)$, normal $\left(18.5-24.9 \mathrm{~kg} / \mathrm{m}^{2}\right)$, overweight $\left(25.0-29.9 \mathrm{~kg} / \mathrm{m}^{2}\right)$ and obese $\left(\geq 30 \mathrm{~kg} / \mathrm{m}^{2}\right)$. Waist circumference was measured midway between the lowest rib and the superior border of the iliac crest. Abdominal obesity was defined as waist circumference $>88 \mathrm{~cm}$ (Grundy et al., 2005). Blood pressure was measured on a single occasion by non-physician trained interviewers. Two measurements of blood

Table 1

Participant's characteristics in the overall study sample and those with fasting blood sample (Portugal, 2009-2011).

\begin{tabular}{|c|c|c|}
\hline & All women & With fasting blood sample \\
\hline & $\mathrm{n}=5435$ & $\mathrm{n}=2483$ \\
\hline \multicolumn{3}{|l|}{ Age (years), $n(\%)$} \\
\hline$<25$ & $240(4.4)$ & $115(4.6)$ \\
\hline $25-29$ & $829(15.2)$ & $407(16.4)$ \\
\hline $30-34$ & $1780(32.8)$ & $819(33.0)$ \\
\hline $35-39$ & $1784(32.8)$ & $795(32.0)$ \\
\hline$\geq 40$ & $802(14.8)$ & $347(14.0)$ \\
\hline \multicolumn{3}{|l|}{ Gravidity, $n(\%)$} \\
\hline 1 & 2007 (36.9) & $926(37.3)$ \\
\hline 2 & $2172(40.0)$ & $1014(40.9)$ \\
\hline$\geq 3$ & $1256(23.1)$ & $543(21.9)$ \\
\hline \multicolumn{3}{|l|}{ Marital status, $n(\%)$} \\
\hline Married/living with a partner & $4843(89.1)$ & $2177(87.7)$ \\
\hline Single/divorced/widow & $592(10.9)$ & $306(12.3)$ \\
\hline \multicolumn{3}{|l|}{ Education (years), $n$ (\%) } \\
\hline$\leq 4$ & $345(6.4)$ & $177(7.1)$ \\
\hline $5-9$ & $2088(38.4)$ & $968(39.0)$ \\
\hline $10-12$ & $1516(27.9)$ & $671(27.0)$ \\
\hline$>12$ & $1486(27.3)$ & 667 (26.9) \\
\hline \multicolumn{3}{|l|}{ Working condition, $n(\%)$} \\
\hline Employed & $4117(75.8)$ & $1869(75.3)$ \\
\hline Unemployed & $928(17.1)$ & $446(18.0)$ \\
\hline Housewife & $254(4.7)$ & $106(4.3)$ \\
\hline Others & $136(2.5)$ & $62(2.5)$ \\
\hline \multicolumn{3}{|l|}{ Household monthly income (€), $n(\%)$} \\
\hline$<500$ & $224(4.1)$ & $125(5.0)$ \\
\hline $500-1000$ & $1296(23.9)$ & $641(25.8)$ \\
\hline $1001-1500$ & $1523(28.0)$ & $648(26.1)$ \\
\hline$>1500$ & $2304(42.4)$ & $1030(41.5)$ \\
\hline Does not know/prefers not to answer & $88(1.6)$ & $39(1.6)$ \\
\hline
\end{tabular}

pressure separated by at least 5 min were taken with an automatic upper arm blood pressure monitor (OMRON M6 comfort (HEM-7000-E)) after 10-minute rest, on the dominant upper arm resting at the heart level. The mean was calculated and when the difference was larger than $5 \mathrm{~mm} \mathrm{Hg}$ for systolic or diastolic blood pressure a third measurement was taken and the mean of the 2 closest values was considered. Arterial hypertension was defined as systolic and/or diastolic blood pressure $\geq 140 / 90 \mathrm{~mm} \mathrm{Hg}$ (Hypertension Guidelines, 2007) and/or self-reported antihypertensive drug therapy prescribed for hypertension.

Dyslipidemia was considered when one of these conditions was verified: total cholesterol $\geq 240 \mathrm{mg} / \mathrm{dL}$, high-density lipoprotein (HDL) $\leq 40 \mathrm{mg} / \mathrm{dL}$, low-density lipoprotein (LDL) $\geq 160 \mathrm{mg} / \mathrm{dL}$, triglycerides $\geq 200 \mathrm{mg} / \mathrm{dL} \mathrm{Na}$ tional (Third Report, 2002) or self-reported antidyslipidemic drug therapy. Diabetes mellitus was defined as fasting plasma glucose concentration $\geq 126 \mathrm{mg} / \mathrm{dL}$ (WHO, 1999) or self-reported antidiabetic drug therapy prescribed specifically for diabetes.

Statistical analysis was performed using the statistical software Stata 9.0 (College Station, TX, 2005). Cardiovascular risk factors were grouped into unfavorable lifestyles (smoking, low fruit and vegetable intake, and sedentariness), adiposity (overweight/obesity and abdominal obesity) and cardiometabolic risk factors (hypertension, dyslipidemia and diabetes mellitus). Possible combinations of the presence of at least one factor from each group were analyzed, in the subsample with information on all risk factors. Unconditional binary logistic regression models were fitted to compute age-adjusted odds ratios (OR) and $95 \%$ confidence intervals $(95 \% \mathrm{CI})$ for dichotomous risk factors, and multinomial logistic regression models for BMI and smoking status, taking BMI $<25 \mathrm{~kg} / \mathrm{m}^{2}$ and never smokers as reference classes, respectively.

The study protocol was approved by the Ethics Committee of Hospital de São João and by the Portuguese Authority of Data Protection. Written informed consent was obtained from the participants.

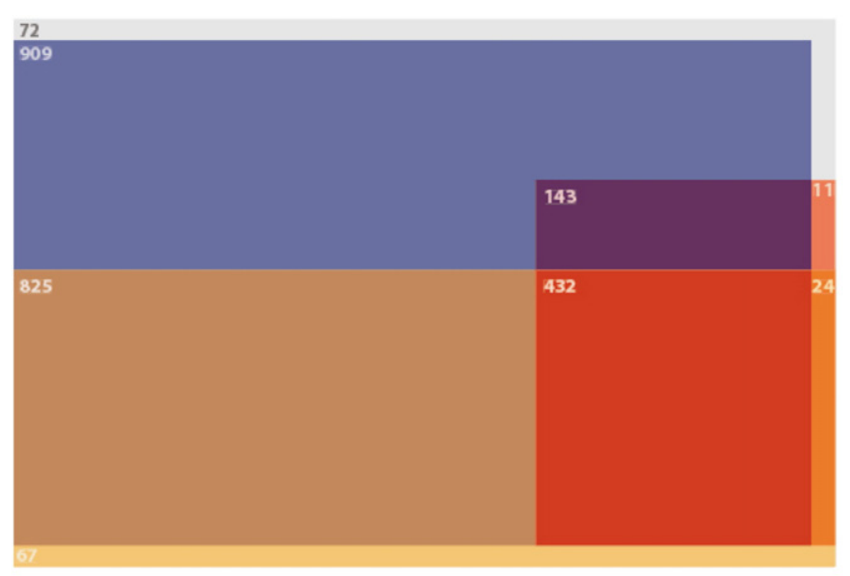

NO RISK FACTORS [72]

UNFAVORABLE LIFESTYLES [909]

ADIPOSITY [67]

CARDIOMETABOLIC RISK FACTORS [11]

UNFAVORABLE LIFESTYLES + ADIPOSITY [825]

UNFAVORABLE LIFESTYLES + CARDIOMETABOLIC RISK FACTORS [143]

ADIPOSITY + CARDIOMETABOLIC RISK FACTORS [24]

UNFAVORABLE LIFESTYLES + ADIPOSITY + CARDIOMETABOUC RISK FACTORS [432]

Fig. 1. Number of women with no risk factors or at least one risk factor from each of the 3 groups considered: unfavorable lifestyles, adiposity and cardiometabolic comorbidities (Portugal, 2009-2011). The area of the individual rectangles and overlap areas are proportional to the number of women in the respective level of exposure. Only the subsample with information available for all risk factors was considered $(n=2483)$. 


\section{Results}

Overall, the socio-demographic characteristics of the participants were similar between all the women and those with a fasting blood sample collection (Table 1). Almost half of the mothers were more than 36 years old and approximately $37 \%$ only had the index pregnancy. Most of the mothers were married or lived with a partner, approximately $27 \%$ had $>12$ years of education, more than $75 \%$ were employed and more than $40 \%$ had a household monthly income $>1500 €$.

An average of 4 years after delivery, 25.3\% (95\%CI: 24.1-26.5) of women smoked, while $71.5 \%$ (95\%CI: 70.3-72.7) had a low intake of fruit and vegetables whereas $81.3 \%$ (95\%CI: 80.2-82.3) did not practice physical exercise. At that time, 31.4\% (95\%Cl: 30.2-32.7) were overweight, 21.3\% (95\%CI: 20.2-22.4) obese and 31.8\% (95\%CI: 30.6-33.1) had abdominal obesity. Regarding cardiometabolic comorbidities, 8.7\% (95\%CI: 7.9-9.5) of the women had hypertension and, among those that provided a fasting blood sample collection, the prevalence of dyslipidemia and diabetes mellitus was 18.5\% (95\%CI: 17.0-20.1) and $0.9 \%$ (95\%CI: 0.6-1.3), respectively. Overall, $17.4 \%$ had at least one risk factor from each of the 3 groups (unfavorable lifestyles, adiposity and cardiometabolic comorbidities) and more than 30\% presented both adverse lifestyles and adiposity (Fig. 1).
Above 30 years of age, the prevalence of smoking, low intake of fruit and vegetables and sedentariness was approximately half that of younger women. Those with $\geq 3$ pregnancies were $31 \%$ and $38 \%$ more likely to smoke and to be sedentary, whereas those not living with a partner were almost 3-fold more frequently smokers. In general, adverse lifestyles were inversely associated with education and income, independently of age. When compared with employed women, the unemployed were $40 \%$ more likely to smoke and $24 \%$ more likely to have a low intake of fruit and vegetables, while housewives were $37 \%$ less likely to smoke. Four years after delivery, smokers were $28 \%$ less likely to be obese, while those who did not practice any physical exercise were $27 \%$ more likely to be obese. The prevalence of former smoking increased with age and educational level, and was lower among housewives (Table 2).

Women aged $>40$ years were $62 \%$ more frequently overweight and just above $30 \%$ more likely to have overall and abdominal obesity, compared to women aged $<30$ years. Gravidity was also associated with both outcomes, independently of age. A significant inverse association was observed for education and monthly household for both variables. Women living with a partner were more likely to have excessive weight or abdominal obesity, as well as housewives and unemployed, when compared with employed women (Table 3).

Table 2

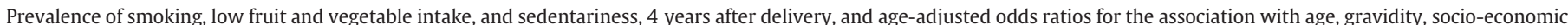
characteristics and BMI, in mothers of a Portuguese birth cohort, 2009-2011 ( $\mathrm{n}=5435$ ).

\begin{tabular}{|c|c|c|c|c|c|c|c|c|}
\hline & \multicolumn{4}{|c|}{ Smoking status ${ }^{\mathrm{a}}$} & \multirow{2}{*}{\multicolumn{2}{|c|}{$\begin{array}{l}\text { Fruit and vegetable intake } \\
<5 \text { portions/day }\end{array}$}} & \multirow{2}{*}{\multicolumn{2}{|c|}{$\begin{array}{l}\text { Physical exercise } \\
\text { Sedentariness }\end{array}$}} \\
\hline & \multicolumn{2}{|l|}{ Current } & \multicolumn{2}{|l|}{ Former } & & & & \\
\hline & $\mathrm{n}(\%)$ & $\begin{array}{l}\text { Age-adjusted } \\
\text { OR }(95 \% \mathrm{CI})^{\mathrm{b}}\end{array}$ & $\mathrm{n}(\%)$ & $\begin{array}{l}\text { Age-adjusted } \\
\text { OR }(95 \% \mathrm{CI})^{\mathrm{b}}\end{array}$ & $\mathrm{n}(\%)$ & $\begin{array}{l}\text { Age-adjusted } \\
\text { OR }(95 \% \mathrm{CI})^{\mathrm{b}}\end{array}$ & $\mathrm{n}(\%)$ & $\begin{array}{l}\text { Age-adjusted } \\
\text { OR }(95 \% \mathrm{CI})^{\mathrm{b}}\end{array}$ \\
\hline \multicolumn{9}{|l|}{ Age (years) } \\
\hline$<30$ & 409 (38.3) & $1^{\mathrm{c}}$ & $136(12.7)$ & $1^{\mathrm{c}}$ & $877(82.0)$ & $1^{\mathrm{c}}$ & $939(87.8)$ & $1^{\mathrm{c}}$ \\
\hline $30-34$ & $424(23.8)$ & $0.49(0.41-0.58)$ & $238(13.4)$ & $0.82(0.65-1.04)$ & $1292(72.6)$ & $0.58(0.48-0.70)$ & $1414(79.4)$ & $0.53(0.43-0.66)$ \\
\hline $35-39$ & $371(20.8)$ & $0.43(0.36-0.51)$ & $303(17.0)$ & $1.05(0.84-1.32)$ & $1201(67.3)$ & $0.45(0.37-0.54)$ & $1397(78.3)$ & $0.50(0.40-0.62)$ \\
\hline$\geq 40$ & $172(21.5)$ & $0.47(0.38-0.58)$ & $164(20.5)$ & $1.36(1.05-1.76)$ & $516(64.3)$ & $0.39(0.32-0.49)$ & $666(83.0)$ & $0.68(0.52-0.88)$ \\
\hline \multicolumn{9}{|l|}{ Gravidity } \\
\hline 1 & $507(25.3)$ & $1^{\mathrm{c}}$ & $295(14.7)$ & $1^{\mathrm{c}}$ & $1508(75.1)$ & $1^{\mathrm{c}}$ & $1605(80.0)$ & $1^{\mathrm{c}}$ \\
\hline 2 & $531(24.5)$ & $1.10(0.95-1.27)$ & $347(16.0)$ & $1.04(0.87-1.24)$ & $1517(69.8)$ & $0.85(0.74-0.98)$ & $1759(81.0)$ & $1.14(0.97-1.33)$ \\
\hline$\geq 3$ & 338 (26.9) & $1.31(1.10-1.56)$ & $199(15.9)$ & $1.01(0.82-1.25)$ & $861(68.6)$ & $0.85(0.72-1.00)$ & $1052(83.8)$ & $1.38(1.14-1.68)$ \\
\hline \multicolumn{9}{|l|}{ Marital status } \\
\hline Married/living with a partner & $1100(22.7)$ & $1^{\mathrm{c}}$ & $772(15.9)$ & $1^{\mathrm{c}}$ & $3453(88.9)$ & $1^{\mathrm{c}}$ & $3940(81.4)$ & $1^{\mathrm{c}}$ \\
\hline Single/divorced/widow & $276(46.6)$ & $2.71(2.24-3.27)$ & $69(11.7)$ & $1.08(0.82-1.43)$ & $433(11.1)$ & $0.97(0.79-1.17)$ & $476(80.4)$ & $0.84(0.68-1.05)$ \\
\hline \multicolumn{9}{|l|}{ Education (years) } \\
\hline$\leq 4$ & $75(21.7)$ & $1^{\mathrm{c}}$ & $43(12.5)$ & $1^{\mathrm{e}}$ & $259(75.1)$ & $1^{\mathrm{e}}$ & 319 (92.5) & $1^{\mathrm{e}}$ \\
\hline $5-9$ & $650(31.1)$ & $1.51(1.13-2.00)$ & $269(12.9)$ & $1.33(0.93-1.91)$ & $1590(76.2)$ & $0.91(0.69-1.19)$ & $1833(87.8)$ & $0.57(0.37-0.87)$ \\
\hline $10-12$ & $377(24.9)$ & $1.23(0.92-1.65)$ & $260(17.2)$ & $1.76(1.23-2.52)$ & $1130(74.5)$ & $0.86(0.65-1.13)$ & $1201(79.2)$ & $0.31(0.21-0.48)$ \\
\hline$>12$ & $274(18.4)$ & $0.96(0.71-1.29)$ & $269(18.1)$ & $1.63(1.14-2.33)$ & $907(61.0)$ & $0.52(0.40-0.68)$ & $1063(71.5)$ & $0.22(0.14-0.33)$ \\
\hline \multicolumn{9}{|l|}{ Working condition } \\
\hline Employed & 985 (23.9) & $1^{\mathrm{c}}$ & $653(15.9)$ & $1^{\mathrm{c}}$ & $2912(74.9)$ & $1^{\mathrm{c}}$ & $3308(80.4)$ & $1^{\mathrm{c}}$ \\
\hline Unemployed & $299(32.2)$ & $1.40(1.19-1.66)$ & $139(15.0)$ & $1.07(0.87-1.31)$ & $707(76.2)$ & $1.24(1.05-1.47)$ & $773(83.3)$ & $1.13(0.94-1.38)$ \\
\hline Housewife & $48(18.9)$ & $0.63(0.45-0.88)$ & $28(11.0)$ & $0.57(0.38-0.85)$ & $171(67.3)$ & $0.84(0.64-1.10)$ & $217(85.4)$ & $1.35(0.94-1.93)$ \\
\hline Others & $44(32.4)$ & $1.35(0.91-1.99)$ & $21(15.4)$ & $1.14(0.69-1.87)$ & $96(70.6)$ & $0.86(0.59-1.26)$ & $118(86.8)$ & $1.45(0.87-2.40)$ \\
\hline \multicolumn{9}{|l|}{ Household monthly income $(€)$} \\
\hline$<500$ & $94(42.0)$ & $1^{\mathrm{c}}$ & $26(11.6)$ & $1^{\mathrm{c}}$ & $166(74.1)$ & $1^{\mathrm{c}}$ & $201(89.7)$ & $1^{\mathrm{c}}$ \\
\hline $500-1000$ & $390(30.1)$ & $0.61(0.45-0.83)$ & $160(12.4)$ & $0.88(0.55-1.40)$ & $976(75.3)$ & $1.12(0.80-1.55)$ & $1129(87.1)$ & $0.81(0.51-1.29)$ \\
\hline $1001-1500$ & $368(24.2)$ & $0.50(0.37-0.68)$ & $239(15.7)$ & $1.09(0.69-1.72)$ & $1169(76.8)$ & $1.26(0.91-1.75)$ & $1303(85.6)$ & $0.74(0.47-1.17)$ \\
\hline$>1500$ & $495(21.5)$ & $0.48(0.36-0.66)$ & $403(17.5)$ & $1.19(0.76-1.86)$ & $1516(65.8)$ & $0.80(0.58-1.09)$ & $1711(74.3)$ & $0.38(0.24-0.59)$ \\
\hline Does not know/prefers not to answer & $29(33.0)$ & $0.77(0.44-1.33)$ & $13(14.8)$ & $1.09(0.51-2.32)$ & $59(67.1)$ & $0.79(0.46-1.36)$ & $72(81.8)$ & $0.53(0.27-1.07)$ \\
\hline \multicolumn{9}{|l|}{ Body mass index $\left(\mathrm{kg} / \mathrm{m}^{2}\right)$} \\
\hline$<24.9$ & $735(28.6)$ & $1^{\mathrm{c}}$ & $384(15.0)$ & $1^{\mathrm{c}}$ & $1878(73.1)$ & $1^{\mathrm{c}}$ & $2071(80.6)$ & $1^{\mathrm{c}}$ \\
\hline $25.0-29.9$ & $378(22.1)$ & $0.72(0.62-0.84)$ & $276(16.2)$ & $0.97(0.81-1.15)$ & $1199(70.2)$ & $0.89(0.78-1.02)$ & $1370(80.2)$ & $0.98(0.84-1.14)$ \\
\hline$\geq 30$ & $263(22.7)$ & $0.72(0.61-0.85)$ & $181(15.6)$ & $0.95(0.78-1.15)$ & 809 (69.9) & $0.86(0.74-1.00)$ & $975(84.3)$ & $1.27(1.06-1.54)$ \\
\hline
\end{tabular}

95\%CI, 95\% confidence interval; BMI, body mass index, OR, odds ratio.

a Reference class of outcome: never smokers.

b Except for age.

c Reference class. 
Table 3

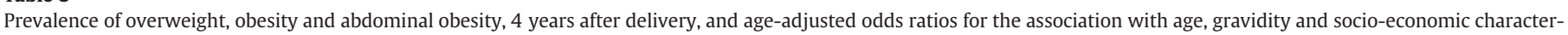
istics, in mothers of a Portuguese birth cohort, 2009-2011 ( $\mathrm{n}=5435$ ).

\begin{tabular}{|c|c|c|c|c|c|c|}
\hline & \multicolumn{4}{|l|}{$\mathrm{BMI}^{\mathrm{a}}$} & \multirow{2}{*}{\multicolumn{2}{|c|}{ Abdominal obesity }} \\
\hline & \multicolumn{2}{|l|}{ Overweight } & \multicolumn{2}{|l|}{ Obesity } & & \\
\hline & $\mathrm{n}(\%)$ & $\begin{array}{l}\text { Age-adjusted } \\
\text { OR }(95 \% \mathrm{CI})^{\mathrm{b}}\end{array}$ & $\mathrm{n}(\%)$ & $\begin{array}{l}\text { Age-adjusted } \\
\text { OR }(95 \% \mathrm{CI})^{\mathrm{b}}\end{array}$ & $\mathrm{n}(\%)$ & $\begin{array}{l}\text { Age-adjusted } \\
\text { OR }(95 \% \mathrm{CI})^{\mathrm{b}}\end{array}$ \\
\hline \multicolumn{7}{|l|}{ Age (years) } \\
\hline$<30$ & $299(28.0)$ & $1^{\mathrm{c}}$ & $240(22.5)$ & $1^{\mathrm{c}}$ & $329(30.9)$ & $1^{\mathrm{c}}$ \\
\hline $30-34$ & $542(30.5)$ & $1.12(0.94-1.34)$ & $380(21.4)$ & $0.98(0.81-1.19)$ & $546(30.7)$ & $1.00(0.84-1.17)$ \\
\hline $35-39$ & $576(32.3)$ & $1.18(0.99-1.41)$ & $346(19.4)$ & $0.89(0.73-1.08)$ & $555(31.1)$ & $1.02(0.86-1.20)$ \\
\hline$\geq 40$ & $292(36.4)$ & $1.62(1.31-2.01)$ & $191(23.8)$ & $1.32(1.04-1.67)$ & $298(37.2)$ & $1.33(1.10-1.62)$ \\
\hline \multicolumn{7}{|l|}{ Gravidity } \\
\hline 1 & $598(29.8)$ & $1^{\mathrm{c}}$ & $382(19.0)$ & $1^{\mathrm{c}}$ & $565(28.2)$ & $1^{\mathrm{c}}$ \\
\hline 2 & $697(32.1)$ & $1.12(0.97-1.29)$ & $447(20.6)$ & $1.18(1.00-1.39)$ & $694(32.0)$ & $1.19(1.04-1.36)$ \\
\hline$\geq 3$ & $414(33.0)$ & $1.28(1.07-1.51)$ & $328(26.1)$ & $1.71(1.41-2.06)$ & $469(37.3)$ & $1.47(1.26-1.72)$ \\
\hline \multicolumn{7}{|l|}{ Marital status } \\
\hline Married/living with a partner & $1539(31.8)$ & $1^{\mathrm{c}}$ & $1052(21.7)$ & $1^{\mathrm{c}}$ & $1588(32.8)$ & $1^{\mathrm{c}}$ \\
\hline Single/divorced/widow & $170(28.7)$ & $0.81(0.66-0.99)$ & $105(17.7)$ & $0.70(0.55-0.88)$ & $140(23.7)$ & $0.63(0.52-0.78)$ \\
\hline \multicolumn{7}{|l|}{ Education (years) } \\
\hline$\leq 4$ & $132(38.3)$ & $1^{\mathrm{c}}$ & $123(35.7)$ & $1^{\mathrm{c}}$ & $169(49.0)$ & $1^{\mathrm{c}}$ \\
\hline $5-9$ & $684(32.8)$ & $0.63(0.47-0.84)$ & $565(27.1)$ & $0.54(0.40-0.73)$ & $817(39.1)$ & $0.73(0.58-0.93)$ \\
\hline $10-12$ & 483 (31.9) & $0.48(0.36-0.65)$ & $284(18.8)$ & $0.30(0.22-0.40)$ & $437(28.8)$ & $0.45(0.36-0.58)$ \\
\hline$>12$ & $410(27.6)$ & $0.32(0.23-0.42)$ & $185(12.5)$ & $0.15(0.11-0.21)$ & $305(20.5)$ & $0.27(0.21-0.35)$ \\
\hline \multicolumn{7}{|l|}{ Working condition } \\
\hline Employed & $1282(31.2)$ & $1^{\mathrm{c}}$ & $778(18.9)$ & $1^{\mathrm{c}}$ & $1185(28.8)$ & $1^{\mathrm{c}}$ \\
\hline Unemployed & 296 (31.9) & $1.33(1.12-1.58)$ & $267(28.8)$ & $1.94(1.62-2.33)$ & $376(40.5)$ & $1.70(1.47-1.98)$ \\
\hline Housewife & $90(35.4)$ & $1.60(1.18-2.17)$ & $75(29.5)$ & $2.19(1.59-3.02)$ & $115(45.3)$ & $2.02(1.56-2.61)$ \\
\hline Others & $41(30.2)$ & $1.19(0.79-1.79)$ & $37(27.2)$ & $1.70(1.12-2.60)$ & $52(38.2)$ & $1.57(1.10-2.34)$ \\
\hline \multicolumn{7}{|l|}{ Household monthly income $(€)$} \\
\hline$<500$ & $75(33.5)$ & $1^{\mathrm{c}}$ & $62(27.7)$ & $1^{\mathrm{c}}$ & $91(40.6)$ & $1^{\mathrm{c}}$ \\
\hline $500-1000$ & $422(32.6)$ & $0.96(0.68-1.34)$ & $370(28.6)$ & $1.02(0.72-1.46)$ & $523(40.4)$ & $0.98(0.73-1.31)$ \\
\hline $1001-1500$ & $494(32.4)$ & $0.83(0.60-1.16)$ & $366(24.0)$ & $0.75(0.53-1.07)$ & $537(35.3)$ & $0.77(0.58-1.03)$ \\
\hline$>1500$ & $693(30.1)$ & $0.58(0.42-0.80)$ & $340(14.8)$ & $0.35(0.24-0.50)$ & $546(23.7)$ & $0.42(0.32-0.56)$ \\
\hline Does not know/prefers not to answer & $25(28.4)$ & $0.61(0.34-1.10)$ & $19(22.5)$ & $0.57(0.31-1.08)$ & $31(35.2)$ & $0.75(0.45-1.26)$ \\
\hline
\end{tabular}

95\%CI, 95\% confidence interval; BMI, body mass index, OR, odds ratio.

a Reference class of outcome: BMI $<25 \mathrm{~kg} / \mathrm{m}^{2}$.

b Except for age.

c Reference class.

Women aged $>40$ years were more likely to have hypertension (6.82-fold), dyslipidemia (1.55-fold) and diabetes (4.57-fold), while obesity was associated with a 4-fold increase in the prevalence of hypertension and a 3-fold increase in the prevalence of dyslipidemia or diabetes. Overall, an inverse association was observed with income for the three cardiometabolic comorbidities, and a similar association was observed with education, with a more relevant effect for hypertension ( $>12$ years vs. $\leq 4$ years: age-adjusted OR $=0.51 ; 95 \%$ CI: $0.35-0.73$ ). Unemployed women were more frequently hypertensive, dyslipidemic or diabetic, when compared with employed women. Marital status was associated with a 3-fold increase in the prevalence of diabetes among women without a partner (Table 4).

\section{Discussion}

In this study, 4 years after delivering a live born, more than $90 \%$ of the participants presented at least one unfavorable lifestyle, more than half had a marker of adiposity and a quarter presented at least one cardiometabolic comorbidity. Overall, $17 \%$ of the women presented an aggregation of factors from all three risk factor groups. Smoking, low fruit and vegetable intake and sedentary lifestyle were more common in younger women, while adiposity and cardiometabolic risk factors were more frequent in older women. The prevalence of hypertension, dyslipidemia, diabetes and sedentariness increased with BMI. Unemployment, education and income were inversely associated with all risk factors, except smoking.
This study quantifies the prevalence of several cardiovascular risk factors in a large sample of young Portuguese women, with the major advantage of objective measurements of weight, height, blood pressure, fasting blood lipids and glucose. Despite the lack of blood sample for the whole cohort, the prevalence of risk factors was not significantly different between women with and without a fasting blood sample (data not shown), making the former subgroup representative of the whole sample.

In Portugal (2005/2006), the prevalence of smoking was 17\% among women aged 15 to 54 years (INS, 2009). This prevalence may have been underestimated, since the questionnaire could be answered by a proxy. Moreover, the higher prevalence of smoking in our sample could reflect its urban nature as well as the higher educational level of the women. The World Health Survey (2002-2003), described a prevalence of fruit and vegetable consumption very similar to the one described, for Spanish women aged $>17$ years (Hall et al., 2009). In 2000, 36.7\% of European female students, aged 18 to 30 years, reported to practice some kind of physical exercise (Steptoe et al., 2002), while less than $20 \%$ of women reported it in the present study. The adverse lifestyles present in this cohort highlight the need for societal change for timely effective cardiovascular prevention. The implications for the health of the family and particularly of their children, both through the shared environment and their responsibility as role models, are a major indirect consequence of these unfavorable behaviors.

In a national survey (2003-2005), the prevalence of overweight and obesity in women aged 18 to 49 years was $34.0 \%$ and $10.6 \%$, respectively, while $11.2 \%$ and $19.9 \%$ of women aged 20 to 29 years and 30 to 39 years 
Table 4

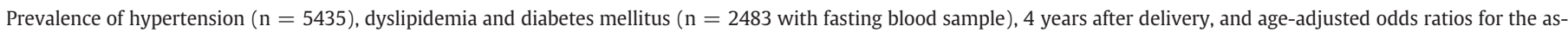
sociation with gravidity, socio-economic characteristics and BMI, in mothers of a Portuguese birth cohort, 2009-2011.

\begin{tabular}{|c|c|c|c|c|c|c|}
\hline & \multicolumn{2}{|c|}{ Hypertension } & \multicolumn{2}{|c|}{ Dyslipidemia } & \multicolumn{2}{|c|}{ Diabetes mellitus } \\
\hline & $\mathrm{n}(\%)$ & $\begin{array}{l}\text { Age-adjusted } \\
\text { OR }(95 \% \mathrm{CI})^{\mathrm{a}}\end{array}$ & $\mathrm{n}(\%)$ & $\begin{array}{l}\text { Age-adjusted } \\
\text { OR }(95 \% \mathrm{CI})^{\mathrm{a}}\end{array}$ & $\mathrm{n}(\%)$ & $\begin{array}{l}\text { Age-adjusted } \\
\text { OR }(95 \% \mathrm{CI})^{\mathrm{a}}\end{array}$ \\
\hline \multicolumn{7}{|l|}{ Age (years) } \\
\hline$<30$ & $33(3.1)$ & $1^{\mathrm{b}}$ & $81(15.5)$ & $1^{\mathrm{b}}$ & $2(0.4)$ & $1^{\mathrm{b}}$ \\
\hline $30-34$ & $117(6.6)$ & $2.21(1.49-3.28)$ & $146(17.8)$ & $1.18(0.88-1.59)$ & $2(0.2)$ & $0.64(0.09-4.53)$ \\
\hline $35-39$ & $179(10.0)$ & $3.50(2.40-5.12)$ & $156(19.6)$ & $1.33(0.99-1.78)$ & $12(1.5)$ & $3.98(0.89-17.88)$ \\
\hline$\geq 40$ & $143(17.8)$ & $6.82(4.62-10.09)$ & $77(22.2)$ & $1.55(1.10-2.20)$ & $6(1.7)$ & $4.57(0.92-22.80)$ \\
\hline \multicolumn{7}{|l|}{ Gravidity } \\
\hline 1 & $152(7.6)$ & $1^{\mathrm{b}}$ & $157(17.0)$ & $1^{\mathrm{b}}$ & $6(0.7)$ & $1^{\mathrm{b}}$ \\
\hline 2 & $187(8.6)$ & $0.90(0.72-1.14)$ & $187(18.4)$ & $1.06(0.83-1.34)$ & $10(1.0)$ & $1.14(0.41-3.21)$ \\
\hline$\geq 3$ & $133(10.6)$ & $0.95(0.73-1.23)$ & $116(21.4)$ & $1.24(0.94-1.63)$ & $6(1.1)$ & $1.12(0.35-3.63)$ \\
\hline \multicolumn{7}{|l|}{ Marital status } \\
\hline Married/living with a partner & $432(8.9)$ & $1^{\mathrm{b}}$ & $409(18.8)$ & $1^{\mathrm{b}}$ & $16(0.7)$ & $1^{\mathrm{b}}$ \\
\hline Single/divorced/widow & $40(6.8)$ & $0.88(0.62-1.23)$ & $51(16.7)$ & $0.90(0.65-1.25)$ & $6(2.0)$ & $3.39(1.29-8.91)$ \\
\hline \multicolumn{7}{|l|}{ Education (years) } \\
\hline$\leq 4$ & $51(14.8)$ & $1^{\mathrm{b}}$ & $32(18.1)$ & $1^{\mathrm{b}}$ & $2(1.1)$ & $1^{\mathrm{b}}$ \\
\hline $5-9$ & $180(8.6)$ & $0.78(0.56-1.11)$ & $195(20.1)$ & $1.26(0.83-1.92)$ & $13(1.3)$ & $1.66(0.36-7.59)$ \\
\hline $10-12$ & $129(8.5)$ & $0.75(0.52-1.07)$ & $126(18.8)$ & $1.14(0.74-1.76)$ & $3(0.5)$ & $0.57(0.09-3.47)$ \\
\hline$>12$ & $112(7.5)$ & $0.51(0.35-0.73)$ & $107(16.0)$ & $0.86(0.55-1.33)$ & $4(0.6)$ & $0.54(0.10-2.99)$ \\
\hline \multicolumn{7}{|l|}{ Working condition } \\
\hline Employed & $337(8.2)$ & $1^{\mathrm{b}}$ & $329(17.6)$ & $1^{\mathrm{b}}$ & $14(0.8)$ & $1^{\mathrm{b}}$ \\
\hline Unemployed & $93(10.0)$ & $1.37(1.07-1.75)$ & $102(22.9)$ & $1.42(1.10-1.83)$ & $6(1.4)$ & $1.79(0.68-4.72)$ \\
\hline Housewife & $30(11.8)$ & $1.43(0.95-2.14)$ & $21(19.8)$ & $1.17(0.71-1.92)$ & $1(0.9)$ & $1.16(0.15-9.00)$ \\
\hline Others & $12(8.8)$ & $1.34(0.72-2.47)$ & $8(12.9)$ & $0.72(0.34-1.53)$ & $1(1.6)$ & $2.63(0.33-20.63)$ \\
\hline \multicolumn{7}{|l|}{ Household monthly income $(€)$} \\
\hline$<500$ & $24(10.7)$ & $1^{\mathrm{b}}$ & $24(19.2)$ & $1^{\mathrm{b}}$ & $2(1.6)$ & $1^{\mathrm{b}}$ \\
\hline $500-1000$ & $130(10.0)$ & $0.89(0.56-1.44)$ & $126(19.7)$ & $1.03(0.63-1.68)$ & $10(1.6)$ & $0.94(0.20-4.41)$ \\
\hline $1001-1500$ & $127(8.3)$ & $0.68(0.43-1.10)$ & $127(19.6)$ & $1.00(0.61-1.63)$ & $6(0.9)$ & $0.54(0.11-2.78)$ \\
\hline$>1500$ & $186(8.1)$ & $0.57(0.36-0.91)$ & $175(17.0)$ & $0.80(0.49-1.29)$ & $3(0.3)$ & $0.14(0.02-0.88)$ \\
\hline Does not know/prefers not to answer & $5(5.7)$ & $0.39(0.14-1.06)$ & $8(20.5)$ & $1.02(0.41-2.50)$ & $1(2.6)$ & $1.21(0.11-14.00)$ \\
\hline \multicolumn{7}{|l|}{ Body mass index $\left(\mathrm{kg} / \mathrm{m}^{2}\right)$} \\
\hline$<24.9$ & $116(4.5)$ & $1^{\mathrm{b}}$ & $135(11.6)$ & $1^{\mathrm{b}}$ & $6(0.5)$ & $1^{\mathrm{b}}$ \\
\hline $25.0-29.9$ & $158(9.3)$ & $2.02(1.57-2.59)$ & $165(21.1)$ & $2.00(1.56-2.56)$ & $6(0.8)$ & $1.40(0.45-4.38)$ \\
\hline$\geq 30$ & $198(17.1)$ & $4.38(3.43-5.59)$ & $160(29.9)$ & $3.24(2.50-4.20)$ & $10(1.9)$ & $3.60(1.30-9.99)$ \\
\hline
\end{tabular}

95\%CI, 95\% confidence interval; BMI, body mass index; OR, odds ratio.

a Except for age.

b Reference class.

presented abdominal obesity (do Carmo et al., 2008). Adiposity is increasing in Portugal, with overweight and obesity prevalences increasing 3.2\% and 7.4\% among women, between 1995 and 2005 (Carreira et al., 2012). Moreover, these women had been pregnant 4 years before, and approximately $20 \%$ had a subsequent pregnancy. Thus, the higher prevalences observed in our study may also reflect an incomplete weight recovery (Amorim et al., 2007).

A systematic review that assessed trends in hypertension prevalence in Portugal, estimated, in 2005, a prevalence of $23.2 \%$ for women at average age 35 years, higher than the one observed in the present study (Pereira et al., 2012). Regarding dyslipidemia, the heterogeneity of definitions among different studies is a universally recognized difficulty for their comparison. No Portuguese study could be identified using similar methodology and criteria. In the United States, the prevalence of high blood cholesterol or low HDL was $25.9 \%$ in women aged between 20 and 39 years (Brown et al., 2000). Among Portuguese women aged 20 to 39 years, the prevalence of type 2 diabetes was $0.6 \%$ (Correia et al., 2010). Since this estimate does not include type $1 \mathrm{di}-$ abetes and $15 \%$ of our cohort was aged above 40 years, the $0.9 \%$ prevalence reported in our study is probably lower than in the general Portuguese female population within this age range. Overall, the lower prevalence of cardiometabolic characteristics in our sample suggests that these women were on average healthier than the general population of the same age group.

The high prevalence of young women with at least one cardiovascular risk factor, as well as their co-occurrence, highlights the adverse cardiovascular profile of these women. Less than $5 \%$ had none of the risk factors studied. The assessment of several risk factors intended to appreciate global cardiovascular risk, beyond the fragmented view of individual risk factors. In Europe, the SCORE system is recommended to evaluate overall CVD risk (Conroy et al., 2003), but it tends to underestimate CVD risk in younger people (Graham et al., 2007). Therefore, we believe that the aggregation of risk factors is more informative of risk at younger ages than a risk score.

We previously reported the pre-pregnancy prevalence of cardiovascular risk factors, in this sample of women based on data self-reported at delivery (Alves et al., 2012). Only 4 years after delivery, the prevalence of all risk factors, except smoking, increased drastically. Overweight/obesity increased from $30.1 \%$ to $52.7 \%$, while the prevalence of hypertension, dyslipidemia and diabetes was 5, 11 and 1.5-times higher, respectively. Although part of this increase may be due to underreport of weight by women (Brunner Huber, 2007) and to the lack of awareness of clinical diagnoses in young ages (Macedo et al., 2005; Scuteri et al., 2009), it is unlikely that these reasons would totally explain such a huge increase in prevalence. When applying a correction factor to the baseline self-reported risk factor prevalence, based on the ratio between the prevalence of objectively defined risk factors and self-reported exposure, calculated in women aged 18 to 40 years from a population-based study from the region of Porto (Pereira et al., 2010) we still observed an increase in prevalence of $15 \%$ for hypertension, $30 \%$ for overweight/obesity, $50 \%$ for diabetes and 8.5 -fold for dyslipidemia. 
In the present study, indicators of socio-economic position were inversely associated with all risk factors. The economic improvements experienced in Portugal in the last decades (Costa et al., 2000), may have contributed to a higher frequency of adverse lifestyles, especially among the lower social classes (Drewnowski and Darmon, 2005; Giles-Corti and Donovan, 2002). In this context, health education should be literacy sensitive in order to enhance health knowledge and self-efficacy to promote the adoption of healthier lifestyles (Osborn et al., 2011).

In conclusion, the prevalence of unfavorable lifestyles and adiposity was very high among women, as early as 4 years after delivery, and the co-occurrence of risk factors emphasizes the unfavorable cardiovascular risk profile at a young age. This is a population expected to be in general healthy and whose characteristics and exposures have implications not only for themselves but also for their children. Also, practically all these women had contact with health care services, mostly the National Health Service which is universal and free of charge in Portugal, and our results show that this opportunity has not been effectively used to control the level of cardiovascular risk within the scope of maternal health care. However, the potential for prevention is vast, especially when considering the modifiable nature of the most important risk factors. These data emphasize the need to implement coherent and effective strategies of health promotion and disease prevention at early stages of life in order to optimize women's current and future health. Since early detection of individuals with modifiable and treatable cardiovascular risk factors may result in saving lives, and reducing the burden of disease and healthcare costs, lifestyle interventions, should be considered a national public policy priority.

\section{Conflict of interest statement}

The authors declare that there are no conflicts of interest

\section{References}

Allender, S., Scarborough, P., Peto, V., et al., 2008. European Cardiovascular Disease Statistics. European Heart Network, Oxford.

Alves, E., Correia, S., Barros, H., Azevedo, A., 2012. Prevalence of self-reported cardiovascular risk factors in Portuguese women: a survey after delivery. Int. J. Public Health 57 (5), 837-847.

Amorim, A.R., Rossner, S., Neovius, M., Lourenco, P.M., Linne, Y., 2007. Does excess pregnancy weight gain constitute a major risk for increasing long-term BMI? Obesity (Silver Spring) 15, 1278-1286.

Brown, C.D., Higgins, M., Donato, K.A., et al., 2000. Body mass index and the prevalence of hypertension and dyslipidemia. Obes. Res. 8, 605-619.

Brunner Huber, L.R., 2007. Validity of self-reported height and weight in women of reproductive age. Matern. Child Health J. 11, 137-144.

Carreira, H., Pereira, M., Azevedo, A., Lunet, N., 2012. Trends of BMI and prevalence of overweight and obesity in Portugal (1995-2005): a systematic review. Public Health Nutr. 1-10.

Conroy, R.M., Pyorala, K., Fitzgerald, A.P., et al., 2003. Estimation of ten-year risk of fatal cardiovascular disease in Europe: the SCORE project. Eur. Heart J. 24, 987-1003.

Correia, L. Boavida, J. Raposo, J. Mesquita A Cardoso, S., 2010. Estudo da prevalência da diabetes em Portugal - PREVADIAB. Sociedade Potuguesa de Diabetologia, Lisboa.

Costa, A., Mauritti, R., Martins, S., Machado, F., Almeida, J., 2000. Classes Sociais na Europa. Sociol. Probl. Prat. 34, 9-43.
Daviglus, M.L., Stamler, J., Pirzada, A., et al., 2004. Favorable cardiovascular risk profile in young women and long-term risk of cardiovascular and all-cause mortality. JAMA 292, 1588-1592.

Direç̧ão-Geral da Saúde (DGS), 2001. Divisão de Saúde Materna, Infantil e dos Adolescentes Saúde Materno-Infantil: Rede de Referenciação Materno-Infantil. DGS, Lisboa.

do Carmo, I., Dos Santos, O., Camolas, J., et al., 2008. Overweight and obesity in Portugal: national prevalence in 2003-2005. Obes. Rev. 9, 11-19.

Drewnowski, A., Darmon, N., 2005. The economics of obesity: dietary energy density and energy cost. Am. J. Clin. Nutr. 82, 265S-273S.

Giles-Corti, B., Donovan, R.J., 2002. Socioeconomic status differences in recreational physical activity levels and real and perceived access to a supportive physical environment. Prev. Med. 35, 601-611.

Graham, I., Atar, D., Borch-Johnsen, K., et al., 2007. European guidelines on cardiovascular disease prevention in clinical practice: executive summary. Eur. Heart J. 28, 2375-2414.

Grundy, S.M., Cleeman, J.I., Daniels, S.R., et al., 2005. Diagnosis and management of the metabolic syndrome: an American Heart Association/National Heart, Lung, and Blood Institute scientific statement. Circulation 112, 2735-2752.

Hall, J.N., Moore, S., Harper, S.B., Lynch, J.W., 2009. Global variability in fruit and vegetable consumption. Am. J. Prev. Med. 36 (402-09), e5.

Hypertension Guidelines, 2007. Summary of the 2007 European Society of Hypertension and European Society of Cardiology guidelines for the management of arterial hypertension. Vasc. Health Risk Manag. 3, 783-795.

Inquérito Nacional de Saúde 2005/2006 (INS), 2009. Instituto Nacional de Saúde Doutor Ricardo Jorge; Instituto Nacional de Estatística: Lisboa.

Instituto Nacional de Estatística (INE), 2012. Estatísticas Demográficas 2010. INE, Lisboa.

Lopes, C., Aro, A., Azevedo, A., Ramos, E., Barros, H., 2007. Intake and adipose tissue composition of fatty acids and risk of myocardial infarction in a male Portuguese community sample. J. Am. Diet. Assoc. 107 (2), 276-286.

Macedo, M.E., Lima, M.J., Silva, A.O., Alcantara, P., Ramalhinho, V., Carmona, J., 2005. Prevalence, awareness, treatment and control of hypertension in Portugal: the PAP study. J. Hypertens. 23, 1661-1666.

McBride, C.M., Emmons, K.M., Lipkus, I.M., 2003. Understanding the potential of teachable moments: the case of smoking cessation. Health Educ. Res. 18, 156-170.

Osborn, C.Y., Paasche-Orlow, M.K., Bailey, S.C., Wolf, M.S., 2011. The mechanisms linking health literacy to behavior and health status. Am. J. Health Behav. 35, $118-128$.

Pereira, M., Azevedo, A., Barros, H., 2010. Determinants of awareness, treatment and control of hypertension in a Portuguese population. Rev. Port. Cardiol. 29, 1779-1792.

Pereira, M., Carreira, H., Vales, C., Rocha, V., Azevedo, A., Lunet, N., 2012. Trends in hypertension prevalence (1990-2005) and mean blood pressure (1975-2005) in Portugal: a systematic review. Blood Press 21 (4), 220-226.

Sattar, N., Greer, I.A., 2002. Pregnancy complications and maternal cardiovascular risk: opportunities for intervention and screening? BMJ 325, 157-160.

Scuteri, A., Najjar, S.S., Orru, M., et al., 2009. Age- and gender-specific awareness, treatment, and control of cardiovascular risk factors and subclinical vascular lesions in a founder population: the SardiNIA Study. Nutr. Metab. Cardiovasc. Dis. $19,532-541$

Stamler, J., 2005. Established major coronary risk factors: historical overview, In: Marmot, L., Elliott, P. (Eds.), Coronary Heart Disease Epidemiology, 2nd ed. From Etiology to Public Health. Oxford University Press, Oxford.

Steptoe, A., Wardle, J., Cui, W., et al., 2002. Trends in smoking, diet, physical exercise, and attitudes toward health in European university students from 13 countries, 1990-2000. Prev. Med. 35, 97-104.

Third Report, 2002. Third Report of the National Cholesterol Education Program Expert Panel on Detection, Evaluation, and Treatment of High Blood Cholesterol in Adults (Adult Treatment Panel III) final report. Circulation 106, 3143-3421.

WHO, 1998. Clinical guidelines on the identification, evaluation, and treatment of overweight and obesity in adults: executive summary. Expert Panel on the Identification, Evaluation, and Treatment of Overweight in Adults. Am. J. Clin. Nutr. 68, 899-917.

WHO, 1999. Diagnosis, and classification of diabetes mellitus and its complications: report of a WHO consultation. Part I: Diagnosis and Classification of Diabetes Mellitus.WHO, Geneva. 